Published as: Liu, X, Derudder, B., Liu, Y., Shen, W. \& Witlox, F. (2013) A stochastic actor-based modelling of the evolution of an intercity corporatenetwork.

Environment and Planning A, Vol. 45 (4), pp. 947-966.

\title{
A stochastic actor-based modelling of the evolution of an intercity corporate network
}

Xingjian Liu (Corresponding author)

Department of Geography, University of Cambridge, Downing Place, Cambridge, UK CB2 3EN.

Email: x1306@cam.ac.uk

Ben Derudder

School of Geography and Environmental Science, Monash University, Australia \& Geography Department, Ghent University, Belgium

Email: ben.derudder@ugent.be

Yaolin Liu

MOE Key Laboratory of GIS and School of Resource and Environmental Science, Wuhan University, China

Email: yaolin610@163.com

Frank Witlox

Geography Department, Ghent University, Belgium

Email: frank.witlox@ugent. be

\section{Acknowledgement}

We thank the editor and three anonymous reviewers for their insightful and constructive comments. The first author is also thankful to Tom Snijders, Johan Koskinen, Guido Conaldi, and Peng Wang for their discussions on network models. The authors gratefully acknowledge financial support from National High-tech R\&D Program of China (2009AA122001; 2011AA120304). The usual disclaimers apply. 


\title{
A stochastic actor-based modelling of the evolution of an intercity corporate network
}

\begin{abstract}
We adopt a stochastic actor-based modeling framework to present a longitudinal analysis of an intercity corporate network formed by 53 globalized advanced producer service firms across 107 cities for three different time points in the period 2000-2010. Our longitudinal framework allows us to investigate the different processes underlying firm networks' dynamics. The observed network changes are explained by a combination of exogenous city characteristics (e.g., GDP and population) and endogenous local network structures (e.g., 'star' and '4-cycle' structures). Our analysis contributes to understanding how interactions amongst cities and firms at the local scale give rise to the empirically observed network patterns at the global scale.
\end{abstract}

\section{Keywords:}

Stochastic-actor based models, two-mode networks, intercity corporate network, network evolution, advanced producer service 


\section{Introduction}

Urban systems are increasingly conceptualised as intercity networks at multiple spatial scales (Anderson et al., 2006), including world city networks (Alderson and Beckfield, 2004), regional urban networks (Yeung, 2000), and the spatial organization of mega-city regions (Pain, 2008). Social network analysis has been widely applied to analyse these urban networks, not in the least because of the conceptual parallels between social network analysis and the analysis of urban networks (see Smith and Timberlake, 1993; Alderson and Beckfield, 2004; Alderson et al., 2010). In Castells' (2001) terms, for instance, cities are to be considered as a set of social processes rather than as a set places, whereby these processes become meaningful through myriad networking practices. For instance, similar to individuals in a social network, cities obtain centrality and power based on their relative positions in the networks inter-connecting them (Neal, 2008).

The conceptual and empirical coupling of the analysis of urban networks with social network analysis has several advantages. On the one hand, social network analysis avoids the reification of cities because it allows for a direct focus on the networking agents connecting cities at different levels. On the other hand, social network analysis may also helps us to address the 'macro-micro problem' (Gondall, 2011), by examining how the observed global network patterns can be linked with network dynamics at local scales. For example, social network analysis could potentially help understanding how interactions among banks in the City of London give rise to London's position as an international financial centre. 
When zooming in on the world city network literature, it can be observed that intercity corporate networks have been a major way of empirically inferring intercity networks (Cooke and Morgan, 1992; Derudder, 2006): cities are deemed connected through the aggregation of intra-corporate organizational linkages. The gist of this 'corporate organisation' approach lies in the assumption that subsidiaries of corporations form intercity networks through their myriad daily operations, whereby leading cities derive their network positions from the multiple presences of important offices in the networks of major firms. Intercity corporate networks are therefore "dual" in the sense that the formation of these networks involves two distinct socialspatial entities: corporations and cities.

Such associations between two different types of entities (cities and firms) are called two-mode networks or bipartite networks in the social network literature (Breiger, 1974; Latapy et al., 2008). Such networks are conceptually different from more commonly studied one-mode networks describing relationships between a single set of nodes (e.g. passenger flows connecting airports). Although less popular analytically, a variety of spatial systems are best described as two-mode networks, including predators and preys in an ecosystem, individuals and events in a neighbourhood, nations and treaties in a multilateral diplomacy, and also firms and cities in an intercity corporate network. Nonetheless, there has been a relative dearth of two-mode network analyses in the urban network literature, which is undoubtedly linked to the higher order of complexity involved in the analysis of two-mode networks. 
In the literature on urban networks, the 'duality' of firms/cities is in practice sidestepped by transforming the dataset into a more conventional one-mode network. Taylor's (2001) much-cited 'specification of the world city network' is essentially such a transformation: the co-location of service firms in cities is used as the input to a projection that yields guesstimates on connectivity in urban networks. Although this approach is most certainly tenable when describing the geographical contours of the world city network (WCN), it does not suffice to analyse the network structure in detail (Neal, 2012). In particular, using a one-mode projection falls short of the full potential of the city/firm database in its depiction of how firms 'use' cities when devising their urbanized corporate networks (Liu and Derudder, 2012). The purpose of this paper is to rectify this state of affairs by presenting a two-mode network analysis of change in the WCN.

In particular, we aim to show the relevance of this two-mode approach by extending existing research on the dynamics of inter-city corporate networks. To date, this literature has either focused on thoroughly describing these changes (e.g., Derudder et al., 2010; Mahutga et al., 2010) and/or explaining these dynamics by correlating them to a series of exogenous variables (e.g., Alderson et al., 2010; Pereira and Derudder, 2010). Using a bipartite network perspective rather than one-mode projections of the city/firm data, however, allows including endogenous dynamics of network formation as cities and firms 'link up' as the WCNs evolve over time.

To this end, in this article, we analyse the evolution of the intercity corporate network as detailed in the data of the Globalization and World Cities (GaWC) research network (http://www.lboro.ac.uk/gawc). We hypothesize the underlying dynamics of 
observed changes with stochastic dynamic actor-based models (Snijders et al., 2010), which are originally developed for modelling of social network dynamics. This new group of stochastic actor-based models seem promising candidates to solving some of the previously discussed issues, as these models are capable of (1) examining twomode city-by-firm data directly; (2) accounting for local dependence among dyads, which reflect local network formation process; and (3) exploring the emergence and evolution of networks over time.

The remainder of this paper is organised as follows. In the next section, we review the analytical frameworks customarily adopted in WCN research, discuss their shortcomings, and explain why a bipartite network perspective may be an effective alternative. We then describe our stochastic actor-based modelling framework, and explain how we generated a longitudinal two-mode dataset linking 107 cities and 53 globalized firms for 2000, 2004, and 2010. We explore this city-by-firm data with stochastic actor-models for two-mode networks, and empirically model the endogenous dependence structures and exogenous city attributes that may contribute to the observed network patterns. We conclude by discussing our results in the context of the empirical WCN literature.

\section{Literature review: frameworks for analysing city/firm relations in}

\section{the world city network}

The key tenet of a two-mode network is that it is characterized by connections between two different sets of network nodes (i.e. cities and firms), whereby there is no (direct) linkage within the same set of nodes (i.e. between cities or between firms). To date, most empirical analyses of two-mode networks in general and intercity 
corporate networks in particular have followed one of two major directions: (1) the conversion into a one-mode network or (2) a direct examination of the dyads.

The first commonly used approach focuses on one particular entity of the two-mode network (Breiger, 1974; Borgatti and Everett, 1997), and derives one-mode city-tocity relationships from two-mode city-by-firm data matrices through network projection (Taylor, 2001; Neal, 2008) or related procedures (Alderson and Beckfield, 2004; Wall, 2009). In addition to satisfying the need of understanding city networks, the advantage of this approach lies in the fact that there are more readily available network analytics for the derived one-mode networks (Borgatti and Everett, 1997). For example, researchers have analysed the resultant city-to-city data with a variety of typical one-mode network analytics, including centrality measures (Neal, 2008), cliques (Derudder and Taylor, 2005), block modelling (Alderson and Beckfield, 2004), and graph visualization (Vinciguerra et al., 2010). The major problem with this approach is that the transformation into a one-mode network causes both a loss of information and inaccurate analytical results (Latapy et al., 2008; Wang et al., 2009). For example, information about network paths of length three or more and/or about nodes with a single connection are lost in the transformation (Wang et al., 2009; Conaldi et al., 2012). Furthermore, the network projection usually creates densely connected one-mode networks (Opsahl, 2012), making it difficult to differentiate network clusters that are generated from generic underlying networking processes from those generated by the network projection itself (Latapy et al., 2008). However, perhaps above all, the problem with this approach is that information about firms is neglected in the transformed city-to-city data, which limits the possibility of exploring 
the role of city/firm-interaction in the formation of the intercity corporate network (Liu and Derudder, 2012).

A second common approach when analysing intercity corporate networks is the direct statistical analysis of the two-mode network dyads (Taylor, 2004; Taylor et al., 2012). By treating the two-mode city-by-firm network as a multivariate dataset, this approach allows for a direct examination of all the information contained within the city-by-firm data matrix. In practice, this implies the use of different multivariate statistical methods, such as principle component analysis (Taylor et al., 2012), discriminant analysis (Taylor, 2004), and cluster analysis (Taylor and Derudder, 2004). However, this straightforward multivariate analysis implicitly assumes that individual firms' locational strategies are statistically independent, while this 'independence' is of course unlikely in reality: it is above all the interdependence between cities and firms that is of interest in the formation of intercity corporate networks. That is, local dependence processes across cities, firms, or firm/citycombinations can generate micro-network structures that reflect the underlying network formation process (Contractor et al., 2006; Robins et al., 2007). For example, cities housing many firms such as London and New York, "star" structures in network terminology, reflect an underlying preferential attachment process, whereby these cities become the "must-be" places for newly established firms. Without incorporating such "star" structures in the evolutionary model, we are essentially assuming that cities with many firms such as London and New York have the same probability of gaining subsidiaries of globalized firms as, say, Leeds or Cincinnati. As a consequence, our models need to account for the interdependence among dyads and 
hypothesize how different local interdependence mechanisms could give rise to the observed network patterns.

Taken together, then, it seems preferable to adopt network analytics that are specifically devised to make full use of the two-mode city-by-firm dataset. Recently developed exponential random graph modelling (ERGM) for two-mode networks (Wang et al. 2009; 2012) offer a possible solution to this interdependence issue in the intercity corporate network, as the ERGM model (1) examines the two-mode network relationships directly, and (2) allows to test different local dependence processes underlying observed networks. Nevertheless, to date ERGMs for two-mode networks are only capable of handling cross-sectional data (Conaldi et al., 2012), and can only be interpreted at (macro-)network level (Desmarais and Cranmer, 2011).

Analysing network formation, however, necessitates longitudinal analyses that explore how networks emerge and evolve over time based on the behaviour of individual actors. Due to the lack of consistent observations of cities and corporations at different time horizons, only a few studies have attempted to measure the temporal dimension of intercity corporate networks. Whereas these studies focus more on describing network changes (Alderson et al., 2010; Derudder et al., 2010) and associating network changes with city-specific covariates (Pereira and Derudder, 2010), generative network models could be useful tools in the empirical testing of network formation processes. The idea behind generative models is to implement the hypothesized network generating process, and to see which network structures emerge using simulation techniques. If the simulated network structures are similar to those observed in reality, it suggests that the hypothesized network generating process may 
drive the formation of the networks (Contractor et al., 2006; Robins et al., 2007). In this article, we propose to analyse the evolution of intercity corporate networks by hypothesizing the underlying dynamics of observed changes with stochastic dynamic actor-based models (Snijders et al., 2010).

\section{Data and Methods}

\subsection{Stochastic Actor-based Models}

Stochastic actor-based models for analysing network dynamics interpret changes in a network as the outcome of network characteristics and structural interdependence among nodes and edges in the network ${ }^{1}$. In this framework, the evolution of a network is treated as a time-continuous stochastic process, whereby empirical observations at specific points in time are assumed to be the emanations of underlying stochastic processes (Snijders, 1996; Snijders, 2001; Snijders et al., 2010). Stochastic actor-based models are in principle agent-based models in the sense that the network dynamics are generated by 'actors' that (1) make rational choices regarding their outgoing ties (Snijders, 2001) and (2) seek to maximize a objective function, given their range of admissible networking behaviours (Warren, 2010). The objective functions represent the micro-mechanisms that influence network changes, and can be defined through different combinations of nodal attributes, linkage properties, and network structures (Snijders et al., 2010).

The goal of stochastic actor-based modelling, then, is to identify the model specification that is most likely to generate the real-world networks observed at

\footnotetext{
${ }^{1}$ This introductory discussion is primarily based on Snijders (2001), Snijders et al. (2007), and Snijders et al. (2010). Readers looking for a complete tutorial introduction to stochastic actor-based models are advised to read Snijders et al. (2010).
} 
discrete points in time. In general, the implementation of a stochastic actor-based model thus involves (1) hypothesizing the potential, underlying network formation process, and implementing these hypotheses into actors' "objective functions"; (2) simulating networks in which individual actors tend to maximize their objective functions; and (3) comparing the simulated network with the observed network (Warren, 2010). This model is iterated until a model specification is found that minimizes the divergence between the simulated and observed networks. In addition, the simulation procedure involves two sub-processes: the change opportunity process and the change determination process (Snijders et al., 2007; Snijders et al., 2010). To introduce these, we first need a formal specification of the time-specific outline of the two-mode network.

Let us suppose a time-series of two-mode networks $X\left(t_{p}\right), t_{p} \in T$, where $T=\{1,2,3, \ldots$, $\mathrm{P}$ \} represents finite observation times whereby $\mathrm{P}$ is no less than 2 . The element $\mathrm{x}_{\mathrm{i}, \mathrm{j}}$ describes the status of the network tie that emanated from node $i$ of the first mode (the "senders") to node $\mathrm{j}$ of the second mode (the "receivers") at a certain time horizon. For two-mode networks, only nodes in the first mode (the "senders") are allowed to change their outgoing ties (Koskinen and Edling, 2010). In our case of intercity corporate networks, firms are the "senders" that connect with cities as "receivers" by establishing branches. A value of 1 indicates the presence of a network tie, 0 the absence of a network tie. The number of nodes in both modes are fixed (Huisman and Snijders, 2003) and denoted as $\mathrm{n}$ and m, respectively. When the network tie between sender $\mathrm{i}$ and receiver $\mathrm{j}$ changes $\left(\mathrm{x}_{\mathrm{i}, \mathrm{j}}\right.$ changes from 0 to 1 , or from 1 to 0 ), we denote the resulting network as $\mathrm{X}(\mathrm{i} \rightarrow \mathrm{j})$ (Warren, 2010). 
The change opportunity process, now, determines the frequency at which a "sender" can change its association with the "receivers". This change opportunity process is implemented as a rate function, which specifies the rate at which "sender" i could change its outgoing times at $t_{p}$ :

$$
\lambda_{i}\left(\alpha, X\left(t_{p}\right)\right), i=1,2,3 \ldots n
$$

where $\alpha$ represents the change rate, and the change rates of individual actors may be constant and equal over time, or depend on network positions and/or attributes of actors (Snijders et al., 2010). Because the data we are working with in this paper only includes observations at three time horizons $(2000,2004,2010)$, we will focus on modelling the change determination process, and will not consider endogenous or exogenous effects on change rate.

The change determination process, in turn, models the probability of an actual network change when an actor acquires the opportunity to make a change in the context of the change opportunity process. The "utility" or the objective for "sender" $i$ to change its network tie to "receiver" $\mathrm{j}$ is summarized by the following objective function:

$$
f_{i}(\beta, X(i \rightarrow j)), i=1,2,3 \ldots n, j=1,2,3 . . m
$$

Given that actor $\mathrm{i}$ has multiple admissible actions when it is granted an opportunity to change outgoing ties, the conditional probability of "sender" $\mathrm{i}$ changing its relation to "receiver" $\mathrm{j}$ is defined as: 


$$
p_{i j}(\beta, X)=\frac{\exp \left(f_{i}(\beta, X(i \rightarrow j))\right)}{\sum_{l=1}^{m} \exp \left(f_{i}(\beta, X(i \rightarrow l))\right)}, i=1,2,3 \ldots n, j=1,2,3 . . m
$$

The combination of the rate function and objective function defines a time-continuous Markov Chain, with the following intensity matrix (Snijders, 2001):

$$
q_{i j}(X)=\lambda_{i}(\alpha, X) p_{i j}(\beta, X)
$$

Moreover, the objective function of actor i depending on the status of network X can be defined as a linear combination of network effects (Snijders et al., 2010):

$$
f_{i}(\beta, X)=\sum_{k} \beta_{k} s_{k i}(X)
$$

The effects function $s_{k i}(X)$ represent network structures or attributes that are (potentially) relevant to actor i's decision on changing a tie, which de facto implies implementing hypotheses on the underlying network formation process. These effects functions can be derived by counting local structures of network $X$, summarizing attributes of individual actors, as well incorporating properties of individual ties. The weights $\beta_{k}$ are statistical parameters that represent the relative importance and statistical significance of individual effects.

Rate parameters and effects parameters that minimize the divergence between simulated and observed networks are then estimated through network simulations. 
Unlike traditional agent based modelling, however, stochastic actor-based models allow statistical inference on effect parameters based on additional simulations (Snijders 2005; Snijders et al., 2010). A positive and significant $\beta_{k}$ suggests that the network tends to change in the direction with a higher corresponding effect, while a negative and significant $\beta_{k}$ suggests that the network tends to change in the direction with a lower corresponding effect (Snijders et al., 2010).

For example, a 4-cycle of two cities and two firms is formed when two firms have offices in the same two cities. The formation of 4-cycle network structures over time, then, reflects the network-generating process whereby firms tend to copy the location strategies of other firms. Similarly, the dissolution of 4-cycle network structures over time suggests that firms remove the locations they share with other firms in other cities. We will elaborate the specification and implications of individual network effects in section 3.3.

\subsection{An Intercity Corporate Network}

The intercity corporate network examined in this paper is derived from what is perhaps the most innovative two-mode dataset on corporate networks, i.e. the GaWC datasets detailing the location strategies of advanced producer service (APS) firms for the years of 2000, 2004 and 2010 (see Taylor, 2004; Taylor et al., 2010; and Taylor et al., 2012 for detailed descriptions about the collection and properties of the GaWC dataset). These globalized APS firms serve as important network agents among world cities, producing an intercity corporate network that reflects worldwide economic linkages (Sassen, 2001; Taylor, 2004). The original GaWC datasets include 100 firms across 315 cities for 2000, 92 firms across 307 cities for 2004, and 175 firms across 
526 cities for 2010, detailing the importance of individual branches within firms' office network. However, for reasons of consistency, our analysis is restricted to (1) the 53 firms appearing in all three datasets (i.e. firms that have remained leading APS providers during the period 2000-2010); (2) major offices (e.g., global and regional headquarters - i.e. offices scoring 4 or 5 in the GaWC data), as these offices represent the backbones of the intercity corporate network; and (3) the 107 cities that have hosted major offices of the selected 53 firms in 2000, 2004, and 2010.

[Table 1 about here]

The resulting dataset comprises three two-mode adjacency matrices, representing the intercity corporate network formed by 53 advanced producer service firms across 107 cities for the years of 2000, 2004 and 2010 (Table 1). A matrix value of 1 and 0 indicates the presence and absence of a major office, respectively. This intercity corporate network has remained largely constant between 2000 and 2004, and expanded between 2004 and between 2010, respectively: there are 207 major offices in 2000, 197 in 2004, and 334 in 2010. The network has also become more connected, as the density of the intercity corporate network evolved from 0.037 in 2000 , to 0.035 to 2004 , and to 0.055 in 2010 . In the first period (2000-2004), 105 major offices remained in place, while 92 and 102 offices were closed/downgraded or opened/upgraded, respectively. In the second period (2004-2010), 95 major offices remained in place, while 219 and 102 offices were closed/downgraded or opened/upgraded, respectively. There are obviously major inequalities in firms and cities' connectedness in this intercity corporate network, as suggested by the right skewed degree distributions of firms and cities (Figure 1). 
Finally, to control for exogenous effects in the network dynamics, we also compiled data on gross domestic product (GDP) and population (POP) for the 107 cities (Pereira and Derudder, 2010; Liu et al., 2011), and create three additional dummy variables (PAC, NAM, and EUR) to indicate whether the cities are located in the three regions where leading cities are located: Pacific Asia, North America, and Europe (Friedmann, 1986; Taylor, 2004).

Despite providing the basis for a consistent and longitudinal study of an intercity corporate network, our datasets also have several limitations: (1) The assigning of 'importance' to offices in the GaWC data gatherings involves a degree of subjectivity, which may create both longitudinal inconsistencies and analytical biases when only certain types of offices are included in the study. However, our focus on the global and regional headquarters is probably less prone to these caveats, as assessments of these important offices are more robust (Liu and Taylor, 2011). (2) We assume that cities' relative population and GDP are constant during our study period, as multiyear consistent urban statistics are hard to be obtained (Liu et al. 2011). For most cities in our study, the population and GDP data are gathered for 2010. (3) The definition of cities can also generate uncertainties in the analysis, as different delimitation of cities' boundaries can result in different distribution and aggregation of population, GDP, and offices. As there is usually no agreement on the territorial definition of cities, we choose to use Metropolitan Statistical Area for US cities, NUT-3 for most European cities, and administrative boundaries for other cities. (4) Stochastic actor-based models assume the length of each time periods in the model to 
be equal, however our first and second study periods are slightly different (four and six years, respectively).

\subsection{Model Specification and Estimation}

The model specification involves the determination of rate and effects parameters. We specify two rate parameters to capture the frequency at which firms decide to change their locational strategies by opening/closing a major office (i.e., changing ties in the two-mode intercity corporate network) during the two study periods. The parameter estimates approximate the average number of changes in locational strategies during a time period.

The selected endogenous network effects represent our hypotheses about the firm/city interplay over time, in addition to the exogenous effects such as GDP or population

growth (Table 2). The selection of hypothetical endogenous network effects is discussed below, whereby - following Warren (2010) - we illustrate how these hypotheses are transformed into network effects statistics.

[Table 2 about here]

A first endogenous effect included is the Density (Outdegree) effect, which captures the general propensity of firms to establish major offices in cities during the period under investigation. A positive Density parameter suggests that firms tend to establish many regional and global headquarters; a negative Density parameter suggests that firms tend not to establish many regional and global headquarters. This Density effect has little meaning (and importance) in and by itself, as it basically serves as a baseline 
parameter that can be compared with the intercept in a conventional linear regression:

$$
s_{1 i}(X)=\sum_{j} x_{i j}
$$

The Firm activity effect explores how existing number of major branches affect firms' expansion, and is implemented in association with the outdegree of firms. A positive parameter associated with the Firm activity effect suggests that individual firms with many major offices in t tend to continue their global expansion and establish more major branches in $\mathrm{t}+1$. Similarly, the City popularity effect tests how existing number of offices in a city influences a city's attractiveness to other firms, and is linked to the indegree of cities (i.e. the number of network ties individual cities receive). A positive parameter for the City popularity effect implies a preferential attachment process, whereby cities with many firms tend to gain more firms. In the preferential attachment scenario, firms tend to cluster to exploit agglomeration economies. The Firm activity and City popularity effects are degree-related effects (Snijders et al., 2010), and represent global hierarchies of firms and cities, respectively: positive parameters imply that the intercity corporate network is moving towards a steeper hierarchy, negative parameters imply that the intercity corporate network is moving towards a less hierarchical outline. Network statistics for these two degree-related effects are calculated as follows:

$$
s_{2 i}(X)=\sum_{j} x_{i j} \sqrt{\sum_{j} x_{i j}}
$$




$$
s_{3 i}(X)=\sum_{i} x_{i j} \sqrt{\sum_{i} x_{i j}}
$$

The use of the square root in both effects can be traced back to mere operational reasons, as square roots generally perform better empirically compared to the raw degree scores (Snijders et al., 2010). Furthermore, the use of square roots is also consistent with the diminishing returns of high degrees (see Derudder et al., 2010), as these are 'compressed' by the use of the square root.

The 4-cycle effect captures the tendency towards (or away from) transitive closure in the formation of the network, whereby globalized firms co-located in a city at t tend to co-locate in more cities at $\mathrm{t}+1$. A 4-cycle of two cities and two firms is formed when two firms $\mathrm{i} 1$ and $\mathrm{i} 2$ have major offices in cities $\mathrm{j} 1$ and $\mathrm{j} 2$. A positive 4-cycle effect suggests that individual firms follow other firms' locational strategies, whereas a negative parameter indicates that individual firms are seeking different niche markets and trying to locate in different cities. This effect is included in the model by counting the number of 4-cycles:

$$
s_{4 i 1}(X)=\sqrt{\sum_{i 1, i 2, j 1, j 2} x_{i 1 j 1} x_{i 1 j 2} x_{i 2 j 1} x_{i 2 j 2}}
$$

In addition, we also include a Firm-city assortativity effect to measure the degree to which active firms are associated with popular cities. A positive value for this parameter suggests that active firms primarily establish new major offices in popular cities, while smaller firms primarily establish new major offices in less popular cities. Negative values would point to saturation effects as active firms are predominantly 
establishing new branches in previously less popular cities. A negative parameter would also suggest a process that mitigates the "gaps" between popular and less popular cities, as the latter are increasingly engaged with more active and thus more globalised firms. This assortativity effect is incorporated into the objective function as follows:

$$
s_{5 i}(X)=\sum_{j}\left(x_{i j} \sqrt{\sum_{i} x_{i j}} \sqrt{\sum_{j} x_{i j}}\right)
$$

In this parameter, the component $x_{i j}$ indicates whether a certain tie exists, whereas $\sqrt{\sum_{i} x_{i j}}$ and $\sqrt{\sum_{j} x_{i j}}$ measure the degrees of firms and cities that are associated with this tie, respectively.

As indicated before, we also specify exogenous city-related covariates to control for individual cities' characteristics that may attract APS firms. The GDP and Population effects measure the degree to which individual cities' market sizes (as approximated by GDP and POP) affect the propensity of individual firms to locate in these cities. Positive parameters associated with these two effects indicate that APS providers tend to locate in larger and richer cities over time:

$$
\begin{aligned}
& s_{6 i}(X)=\sum_{j} x_{i j} G D P_{j} \\
& s_{7 i}(X)=\sum_{j} x_{i j} P O P_{j}
\end{aligned}
$$


And finally, we include dummy variables for cities located in Pacific Asia, North America, and Europe to control for possible regional effects in the changing location of major offices of APS firms in cities across the globe:

$$
\begin{aligned}
& s_{8 i}(X)=\sum_{j} x_{i j} P A C_{j} \\
& s_{9 i}(X)=\sum_{j} x_{i j} N A M_{j} \\
& s_{10 i}(X)=\sum_{j} x_{i j} E U R_{j}
\end{aligned}
$$

In our modelling exercise, we employ a forward model selection strategy and construct a series of nested stochastic actor-based models that progressively include these ten network effects. Model 0 is our null model, whereby the objective function only accounts for the overall Density effect. Model 1 accounts for exogenous citylevel GDP and population covariates (6-7). Model 1 is included in Model 2, as this also incorporates exogenous regional effects (6-10). Meanwhile, Model 3 only considers endogenous network structural effects (1-5), and thus focuses on how firms' locational strategies affect each other's strategies. And finally, Model 4 is a full model that accounts for all previously mentioned endogenous network effects and exogenous covariates $(1-10)$.

Each of the four models is estimated three times, i.e. for the entire $2000-2010$ period (the 'combined model') as well as the 2000-2004 and 2004-2010 periods (the 'separate models'). This allows assessing whether the major network generation processes have been different during the period under investigation. While the world 
economy has in general seen an intense wave of globalisation and economic growth during our first period (2000-2004), the second period (2004-2010) has - especially towards the end - been dominated by economic crisis and concomitant geo-economic shifts. Although these are sweeping statements to say the least, it is worthwhile to assess whether such wider geo-economic changes are visible in the dynamics of the location of major offices of APS firms.

Based on this model specification, we can now address the following questions:

1. What kind of endogenous network structures are most responsible for the dynamics in the intercity corporate network?

2. What kind of exogenous covariates are most responsible for the dynamics in the intercity corporate network?

3. Are changes in the intercity corporate network during the two study periods (20002004 and 2004-2010) characterized by different dynamics?

We estimate our stochastic actor-based models through "Methods of Moments" estimators, and the estimation procedures are repeated for 2000 runs. Wald (Schweinberger and Snijders, 2007) and Score-type (Schweinberger, 2011) tests are computed to assess the model fit (Conaldi et al., 2012). The significance of these two tests reflects the difference in model fit between the null model and more complex models. We also assess models' goodness of fit by comparing degree distributions of networks simulated from constructed models and observed intercity corporate networks (Contractor et al., 2006; Robins et al., 2007; Conaldi et al., 2012). The degree for cities refers to the number of firms they host, and the degree for firms correspond to the number of cities they locate in. The simulation of networks uses 
parameter estimates for the full model and is repeated for 2000 runs. A satisfactory model fit would result in a distribution of observed intercity corporate network that falls within two standard deviations of the means of the 2000 simulated networks (Conaldi et al., 2012). In other words, satisfactory simulated networks would replicate some global properties of the observed network, by incorporating endogenous and exogenous effects at local level. All model specification (Ripley et al., 2012), estimation (Koskinen and Edling, 2011) and simulation (Conaldi et al., 2012) procedures are implemented with the RSiena package on the R platform.

\section{Results}

\subsection{Models for the entire time period $(2000-2010)$}

The parameter estimates for the different models over the entire time period (20002010) are presented in Table 3. All of the estimated parameters have a t-ratio of less than 0.1 in absolute values, indicating the estimation algorithm has reached good model convergence (Snijders et al., 2010). Wald-type tests for joint significance also generate statistically significant results for Models 1-4, indicating that the formation of intercity corporate network is indeed related to exogenous GDP and population covariates of GDP (Model 1), exogenous regional effects (Model 2) and endogenous network structures (Model 3). In addition, we performed score-type tests to ensure that the model fit increases as we include additional effects into the objective function. The significant values of score-types for Model 1-3 suggest improvements in model fit, as new parameters and network statistics are progressively added. We only include two dummy regional variables, as the inclusion of regional effects for North American cities does not generate statistically significant results for the Wald and Score-type tests. 
[Figure 1 about here]

[Table 3 about here]

In the upper half of Figure 1, observed networks are compared with networks that are simulated from Model 4 for both cities and firms in 2004 and 2010. The boxplots represent frequency distributions for different degree values in the 2000 simulations, and the solid blue lines represent the observed degree distribution. For most degree values, the observed distribution falls within two standard deviations of the means of simulated distributions. This observation is also consistent with Table 5, which summarises the deviations between networks statistics of observed and simulated networks. Apart from the skewness of degree distribution of firms, deviations between observed and simulated networks in Table 5 are mostly less than $15 \%$, suggesting a reasonably well model fit.

Rate parameters suggest that there are on average more changes in firms' locational strategies during 2004-2010 than in 2000-2004. For example, Model 4 suggests that firms averagely change their locational strategies 7.5 and 24.8 times for the first and second time periods, respectively. A possible interpretation of this result is that the global economic crisis, which unfolded during the second time period, may have led to a large-scale geographical re-structuring of globalised APS firms. McCauley et al. (2012) for instance, have suggested that the economic crisis and post-crisis regulatory reforms have led to shifts in financial services firms' business models towards more "locally" embedded services, thus increasing the importance of regional offices 
(McCauley et al., 2012). In addition, such decentralisation processes in banking and other APS sectors may have contributed to the increased number of major offices in 2010.

The Density parameter is negative and statistically significant in all models, implying that our baseline model assumes that individual firms are on average not inclined to establish a new major office. Conditional on the Density effect in model 0, exogenous city-level covariates GDP and Population are added in Model 1. A significant and positive parameter for the GDP effects indicates that APS firms tend to locate in the world's richest cities (Pereira and Derudder, 2010). For example, New York and London are the two most connected cities in our intercity corporate network, while these two cities also lead in the GDP ranking. Interestingly, the parameter for the city Population effect is negative and insignificant. This may be consistent with the fact that (1) cities such as Frankfurt, Dubai, and Luxemburg have small populations (Bassens et al., 2010) relative to the size of their clusters of APS firms, primarily in the financial sector; and (2) globalized APS firms have not established large numbers of branches in the world's largest cities, which are increasingly located in the erstwhile 'Third World'.

Model 2 includes two further exogenous regional effects for Pacific Asian and European cities. The regional effect for Pacific Asian cities is positive, suggesting that Pacific Asian cities have on average attracted more major offices. The negative parameter for European cities, in turn, implies that these cities have on average attracted less new firms (ceteris paribus). 
Model 3, which only incorporates endogenous network effects, reveals a positive and statistically significant Firm activity effect. This implies that firms with many major offices across the world in $t$ have tended to establish more branches in $t+1$, generating a steeper hierarchy among firms in terms of their degree of global presence over time. A positive and significant City popularity effect is also found, which shows that cities hosting many firms tend to attract more firms. As mentioned previously, this positive City popularity effect indicates a preferential attachment process, i.e., the Matthew effect (Barabási and Albert, 1999) in the formation of intercity corporate networks. This implies that cities like New York and London strengthen their position over time as these cities become "must-be" places for APS firms, implying that that major APS firms tend to establish new major offices or upgrade the status of their existing offices in these cities. This preferential attachment is also at least partly responsible for the inequality in cities' connectivity: a few cities host many major offices of APS firms, whereas most cities have a small number of such major offices. This preferential attachment process is consistent with previous finding on the hierarchical tendencies in the APS networks of cities (Derudder et al., 2003; Neal, 2008), and similar preferential attachment processes have been identified for the generation of other intercity networks (Vinciguerra et al., 2010).

The parameter for Firm-city assortativity effect is negative and significant, suggesting that, everything else being equal, active firms also progressively engage more with less popular cities, as most of these active firms already have established branches in popular cities (see the combined effects of Firm Activity and City Popularity). Model 3 also features a positive and significant 4-cycle effect, which suggests 'coupling' among firms' locational strategies (Gondall, 2011). In other words, firms that co- 
locate in city A, but not in city B at t (i.e. only one of the firms has a major office in city B), are more likely to also co-locate in city $\mathrm{B}$ at $\mathrm{t}+1$. The positive 4 -cycle effect again strengthens the "preferential attachment process" and further facilitates the hierarchical processes within the intercity corporate networks, forming densely interconnected "cores" in the world city system (Alderson and Beckfield, 2004).

Model 4 combines all endogenous and exogenous effects. The significance and sign of parameters included in previous models remain the same, except that the parameters for 4-Cycle and Firm-city assortativity effects become insignificant. This could be ascribed to the fact that degree-based endogenous effects such as 4-Cycle may be correlated with exogenous variables (Snijders et al., 2010). For example, if firms tend to co-locate over time (and thus form 4-Cycles) in rich cities with large GDP outputs, then the ensuing covariation will result in less significant parameters for both variables. Moreover, we note that estimates for 4-Cycle and Firm-city assortativity in Model 3 are within two standard deviations from estimates in Model 4, suggesting consistencies between Model 3 and 4.

When models 0-4 are jointly interpreted, we can conclude that the core dynamics in the intercity corporate network can be understood as a combination of hierarchical tendencies (positive City popularity, Firm activity, and Firm-city assortativity), cities socioeconomic stature (GDP and population), regional disparities (Pacific Asian and European effects) as well as interactions among firms' locational strategies (4-Cycle). In addition, as parameter estimates and network status can be used to calculate the log odds ratio between different admissible changes (Snijders, 2001; Snijders et al., 2010), this helps us understand (1) the relative impact of individual parameters; and 
(2) assess the probabilities of future network status ${ }^{2}$. Two brief examples should clarify the analytical possibilities this offers. First, in the baseline model (Model 1), an average firm has a probability of $0.178\left(\exp ^{-1.526} /\left(\exp ^{-1.526}+1\right)\right)$ to open/upgrade a new major office. Second, suppose that city A and city B have exactly the same values for all endogenous and exogenous effects included in Model 4, except that city A lies in Pacific Asia. Everything else being equal, the probability for City A to acquire an additional major office is at least $1.213\left(\exp ^{0.193}\right)$ times higher than the probability for City B to host a new major office. The log odds for more complex scenarios can be computed in a similar fashion, but with less straightforward interpretations (Snijders, 2005; Snijders et al., 2010).

\subsection{Breakdown of models for the two time periods (2000-2004 and 2004-2010)}

The models discussed in 4.1 pertain to the entire 2000-2010 time period, assuming homogeneity of underlying dynamics for the two time periods. However, it is possible that different network dynamics can be observed for the first (2000-2004) and the second (2004-2010) time period, which can in turn be related to different cycles in global economic development. To this end, we model the network dynamics in each of the two time periods independently (i.e. the 'separate models'), and evaluate how these dynamics deviate from those derived from models for the entire time period (i.e. the 'combined model') (Table 4).

[Table 4 about here]

\footnotetext{
${ }^{2}$ However, unlike conventional regression analysis, parameters in stochastic actor-based models are unstandardized and cannot be used to compare the size of effects directly.
} 


\section{[Table 5 about here]}

Fitting the separate models improves the model fit (the lower half in Figure 1), as the simulated degree distributions are more centred on the observed distributions (i.e., there are less outliers in the boxplots). Moreover, the deviations between observed and simulated models, except for the skewness of the degree distributions for firms, are less than $10 \%$ for the separate models (Table 5). Most importantly, however, it can be seen that the estimated parameters for these separate models are largely in accordance with those for the combined model (Table 4). In other words, most parameter estimates of the combined model, regardless of their significance, fall within two standard deviations of estimates of separate models (Snijders, 2005). For example, the negative Density effect, positive City Popularity effect, and positive Firm Activity effect are significant in both combined and separate models, reflecting a continuous hierarchical process in the formation of intercity corporate networks. In addition, the positive GDP effect remains significant in all three models.

The most clear-cut difference between the separate models for 2000-2004 and 20042010 is that the regional effects are significant for the second period but not for the first. More specifically, both exogenous regional effects for European and Pacific Asian cities are insignificant for 2000-2004, whereas the separate model for 20042010 features a positive and significant Pacific-Asian effect as well as a negative and significant European effect. This is in line with earlier observations regarding the rise 
of Pacific Asian (and especially Chinese) cities in the world city network over the past few years (Derudder et al., 2010; Taylor et al., 2012).

\section{Conclusions}

Previous longitudinal analyses of transnational urban networks have not exploited the appropriate two-mode analytics that reflect the city/firm data structure (Neal, 2012; Liu and Derudder, 2012). In this paper, we therefore adopted a stochastic actor-based modelling framework, and carried out a longitudinal analysis of an intercity corporate network formed by 53 globalized advanced producer service firms across 107 cities between 2000 and 2010 (with an intermediate data point in 2004). Our analysis contributes to the empirical world city network literature in the sense that it (1) involves a direct examination of the two-mode intercity corporate network; and (2) models the observed network changes as driven by both exogenous effects of city characteristics and endogenous effects of local network structures.

The stochastic actor-based modelling framework allows - over and beyond estimating the effects of commonsensical exogenous effects such as GDP and population - to link the hypothesised underlying network effects at the local level with the overall observed network patterns, and assess the significance and relative importance of these network effects. We find that positive and significant Firm activity and City popularity contribute to the steep hierarchy in the degree distribution of firms and cities, respectively. In addition to the City popularity effects, active firms tend to locate their new major offices in previously less popular cities, resulting in a diverse set of well-connected cities. In addition, firms prefer to locate their major branches in cities with a large GDP, while Pacific Asian cities have been attracting more APS 
firms. There is also a significant and positive 4-Cycle effect in the network formation, suggesting that firms' locational strategies are inter-connected. However, this effect correlates with other exogenous variables and is no longer significant in the full model. Network dynamics of the separate models for 2000-2004 and 2004-2010 are in general consistent with those estimated for the combined model, albeit that regional effects are more evident during the second time period.

Although unveiling these endogenous network effects allows for a more nuanced analysis of change in the world city network, our analysis could be improved in at least three directions. Firstly, the model specification could be pruned and include more complex network effects, such as those placing more importance on the elimination of a tie (Snijders et al., 2010). In addition, we could include more actorspecific covariates, as we do not have any firm-related exogenous effects in our current specification. Secondly, our analysis could be improved by generating spatialexplicit stochastic actor-based models that explicitly account for geographic factors in the objective function. The geographic factor is modelled implicitly as regional effects in our current study. While attempts for spatial-explicit stochastic actor-based models have been made for one-mode networks (Warren, 2010), no such spatialexplicit models for two-mode networks have been devised. Thirdly, we could validate the robustness of our analysis by modelling intercity corporate networks at multiple spatial scales. For example, it is in principle possible to cross-check modelling results of the global network and regional sub-networks. However, despite these and other options for improvement, we believe our current analysis has demonstrated the stochastic actor-based models' capability in linking observed network changes with various hypothesized network effects. 



\section{Tables and Figures}

Table 1. Descriptive network statistics

Table 2. Network effects for the two-mode intercity corporate network

Table 3 Forward model selection and estimated models

Table 4 Combined and separate simulation results

Table 5 Goodness of fit for (a) combined simulations and (b) separate simulations

Figure 1 Simulated and observed degree distributions. (The box plots represent simulated degree distributions for firms and cities, while the thick blue lines represent observed distributions. Cities with an indegree of less than 16 and firms with outdegree less than 16 are depicted in the figure). 
Table 1 Descriptive network statistics

\begin{tabular}{|l|l|l|l|}
\hline Statistics & GaWC 2000 & GaWC 2004 & GaWC 2010 \\
\hline Nodes & 107 cities and 53 firms \\
\hline Potential ties & 5671 & \multicolumn{2}{|l|}{} \\
\hline Density & 0.037 & 0.035 & 0.055 \\
\hline Average degree & 3.906 & 3.717 & 5.925 \\
\hline Existing ties & 207 & 197 & 314 \\
\hline & & & \\
\hline Changes & $2000 \rightarrow 2004$ & $2004 \rightarrow 2010$ & \\
\hline Jaccard index & 0.351 & 0.228 & \\
\hline $0 \rightarrow 0$ & 5372 & 5255 & \\
\hline $0 \rightarrow 1$ & 92 & 219 & \\
\hline $1 \rightarrow 0$ & 102 & 102 & \\
\hline $1 \rightarrow 1$ & 105 & 95 & \\
\hline
\end{tabular}

1. The Jaccard Index is calculated as $\mathrm{N}_{11} /\left(\mathrm{N}_{11}+\mathrm{N}_{01}+\mathrm{N}_{10}\right)$, where $\mathrm{N}_{11}, \mathrm{~N}_{01}, \mathrm{~N}_{10}$ are number of linkages with the statues of $(1 \rightarrow 1),(0 \rightarrow 1)$, and $(1 \rightarrow 0)$, respectively.

2. A Jaccard index greater than 0.2 indicates that the underlying network formation process is suitable to be modeled by stochastic actor-based models (Snijders et al. 2010). 
Table 2. Network effects for the two-mode intercity corporate network

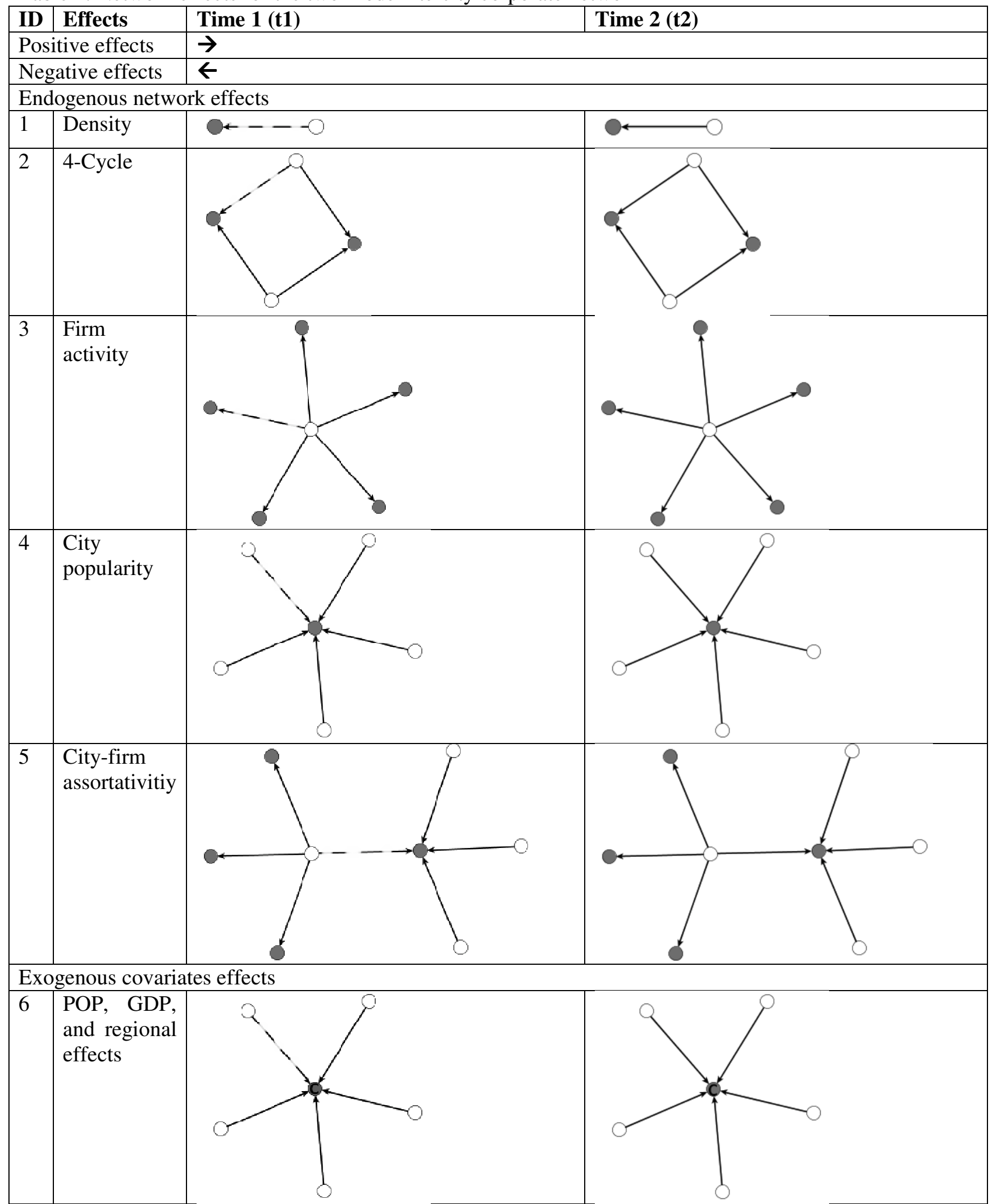

1. Grey circles represent cities, white cirlces represent firms. Circles labelled with "c" denote nodes with particular characteristics.

2. Dash and solid lines represent yet-to-exist and existing network ties, respectively.

3. We only illustrate admissible network changes from t 1 to 2 when the corresponding effects are associated with positive parameters. If the associated parameters are negative, network patterns are more likely to change from configurations in the fourth column (t2) to that in the third column (t1). 
Table 3 Forward model selection and estimated models

\begin{tabular}{|c|c|c|c|c|c|c|c|c|c|c|}
\hline & Model 0 & & Model 1 & & Model 2 & & Model 3 & & Model 4 & \\
\hline & Estimates & Std.Dev & Estimates & Std.Dev & Estimates & Std.Dev & Estimates & Std.Dev & Estimates & Std.Dev \\
\hline \multicolumn{11}{|l|}{ Change rate } \\
\hline Rate $(00-04)$ & 5.121 & 0.430 & 5.855 & 0.558 & 5.861 & 0.566 & 7.359 & 0.886 & 7.493 & 0.874 \\
\hline Rate (04-10) & 12.163 & 1.118 & 16.864 & 2.067 & 16.820 & 2.018 & 22.270 & 4.144 & 24.832 & 9.636 \\
\hline \multicolumn{11}{|c|}{ Endogenous network effects } \\
\hline Density & -1.526 & 0.041 & -1.734 & 0.041 & -1.742 & 0.042 & -4.330 & 0.224 & -4.477 & 0.333 \\
\hline 4-Cycle & & & & & & & 0.519 & 0.218 & -0.122 & 0.326 \\
\hline $\begin{array}{l}\text { City } \\
\text { popularity }\end{array}$ & & & & & & & 0.507 & 0.104 & 0.607 & 0.112 \\
\hline Firm activity & & & & & & & 0.626 & 0.104 & 0.472 & 0.237 \\
\hline $\begin{array}{l}\text { Firm-city } \\
\text { assortativity }\end{array}$ & & & & & & & -0.092 & 0.050 & 0.005 & 0.108 \\
\hline & & & & & & & & & & \\
\hline \multicolumn{11}{|c|}{ Exogenous effects } \\
\hline City POP & & & -0.294 & 0.228 & -0.672 & 0.278 & & & -0.419 & 0.290 \\
\hline City GDP & & & 2.157 & 0.173 & 2.372 & 0.192 & & & 0.797 & 0.243 \\
\hline Pacific Asian & & & & & 0.074 & 0.117 & & & 0.193 & 0.108 \\
\hline European & & & & & -0.203 & 0.090 & & & -0.179 & 0.090 \\
\hline & & & & & & & & & & \\
\hline \multicolumn{11}{|l|}{ Tests } \\
\hline Score-type & & & 314.245 & d.f. $=2$ & 5.873 & d.f. $=2$ & 1835.344 & d.f. $=4$ & & \\
\hline Wald & & & 279.849 & & 5.748 & & 477.127 & & & \\
\hline
\end{tabular}

Note: 1. Estimations for all effects have reached convergence; 2. Parameter estimates in thick letters are significant at 0.1 level. 
Table 4 Combined and separate modelling results

\begin{tabular}{|c|c|c|c|c|c|c|}
\hline & \multicolumn{2}{|c|}{ Combined model for $2000-2010$} & \multicolumn{2}{|c|}{ Separate model for $2000-2004$} & \multicolumn{2}{|c|}{ Separate model for $2004-2010$} \\
\hline & Estimates & Std.Dev & Estimates & Std.Dev & Estimates & Std.Dev \\
\hline \multicolumn{7}{|l|}{ Change rate } \\
\hline Rate (2000-04) & 7.493 & 0.874 & 7.667 & 0.868 & & \\
\hline Rate (2004-10) & 24.832 & 9.636 & & & $\mathbf{1 9 . 1 3 6}$ & 2.726 \\
\hline \multicolumn{7}{|c|}{ Endogenous network effects } \\
\hline Density & -4.477 & 0.333 & -4.670 & 0.360 & -4.379 & 0.290 \\
\hline 4-Cycle & -0.122 & 0.326 & 0.238 & 0.260 & 0.224 & 0.333 \\
\hline City popularity & 0.607 & 0.112 & 0.514 & 0.146 & 0.577 & 0.169 \\
\hline Firm activity & 0.472 & 0.237 & 0.847 & 0.182 & 0.625 & 0.110 \\
\hline $\begin{array}{l}\text { Firm-city } \\
\text { assortativity }\end{array}$ & 0.005 & 0.108 & -0.152 & 0.086 & -0.089 & 0.053 \\
\hline \multicolumn{7}{|c|}{ Exogenous effects } \\
\hline City POP & -0.419 & 0.290 & -0.201 & 0.561 & -0.476 & 0.330 \\
\hline City GDP & 0.797 & 0.243 & 1.293 & 0.487 & 0.919 & 0.319 \\
\hline Pacific Asian & 0.193 & 0.108 & -0.188 & 0.239 & 0.288 & 0.123 \\
\hline European & -0.179 & 0.090 & -0.225 & 0.176 & -0.202 & 0.116 \\
\hline
\end{tabular}

Note: 1. Estimations for all effects have reached convergence; 2. Parameters in thick letters are significant at the 0.1 level. 
Table 5 Goodness of fit for (a) the combined model and (b) the separate models

(a)

\begin{tabular}{|c|c|c|c|c|c|c|c|c|c|c|c|c|c|}
\hline & \multicolumn{6}{|l|}{2004} & & \multicolumn{6}{|l|}{2010} \\
\hline & \multicolumn{3}{|l|}{ Firms } & \multicolumn{3}{|l|}{ Cities } & & \multicolumn{3}{|l|}{ Firms } & \multicolumn{3}{|l|}{ Cities } \\
\hline & Observed & Simulated & $\begin{array}{l}\text { Diff } \\
(\%)\end{array}$ & Observed & Simulated & $\begin{array}{l}\text { Diff } \\
(\%)\end{array}$ & & Observed & Simulated & $\begin{array}{l}\text { Diff } \\
(\%)\end{array}$ & Observed & Simulated & $\begin{array}{l}\text { Diff } \\
(\%)\end{array}$ \\
\hline Degree & 3.717 & 4.226 & 13.695 & 1.841 & 2.093 & 13.695 & Degree & 5.925 & 5.443 & -8.124 & 2.935 & 2.696 & -8.124 \\
\hline Variation & 3.754 & 3.193 & -14.940 & 4.144 & 4.931 & 19.000 & Variation & 5.863 & 6.101 & 4.048 & 5.473 & 4.936 & -9.811 \\
\hline Skew & 2.120 & 1.238 & -41.601 & 5.061 & 5.415 & 6.994 & Skew & 4.317 & 2.789 & -35.384 & 4.442 & 5.015 & 12.892 \\
\hline
\end{tabular}

(b)

\begin{tabular}{|l|l|l|l|l|l|l|l|l|l|l|l|l|}
\hline & \multicolumn{9}{l|}{} & & \multicolumn{2}{l|}{2010} \\
\hline
\end{tabular}


Figure 1 Simulated and observed degree distributions (The box plots represent simulated degree distributions for firms and cities, and the thick blue lines represent observed distributions)

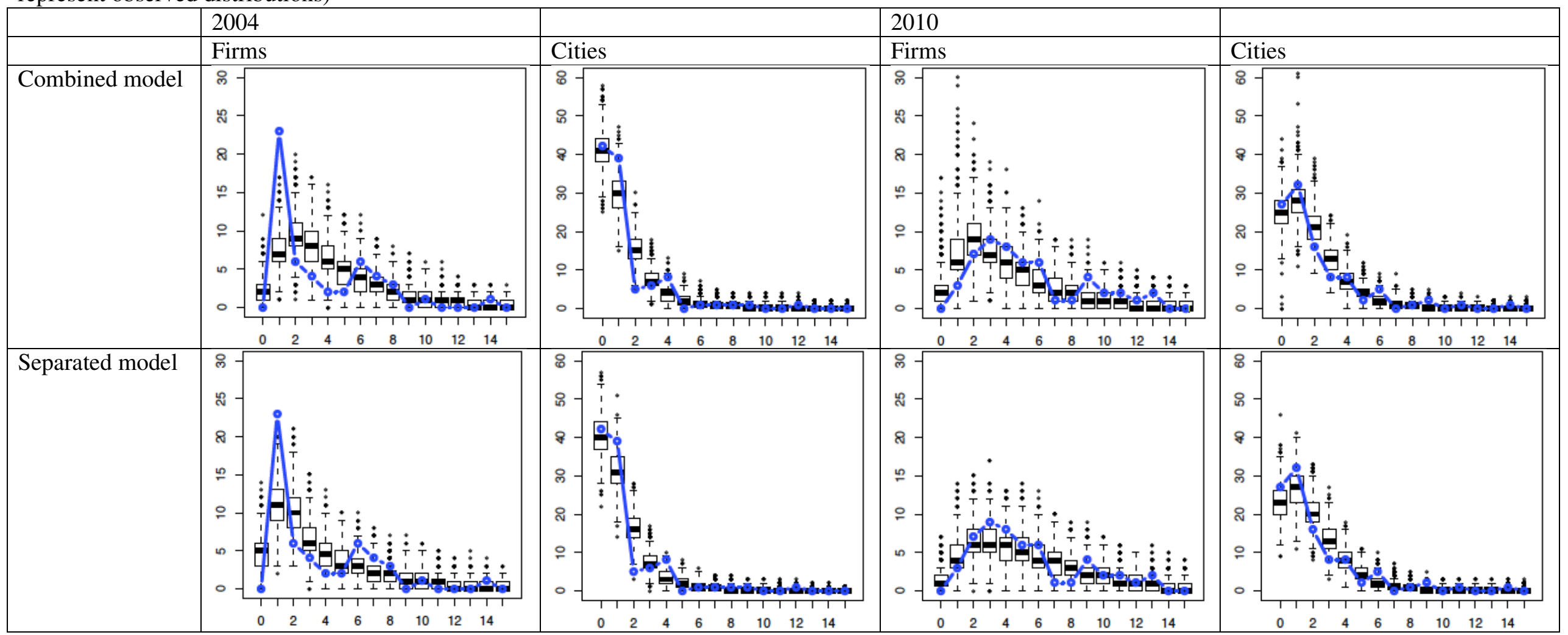

Note: Satisfactory model fits are achieved when the observed degree distributions fall within one standard deviation from the mean of simulated (empirically derived) distributions. 


\section{References}

Alderson A, Beckfield J, 2004, "Power and position in the world city system" American Journal of Sociology 109 811-851

Alderson A, Beckfield J, Sprague-Jones J, 2010, "Intercity relations and globalization: The evolution of the global urban hierarchy, 1981-2007” Urban Studies 47 1899-1923

Andersson C, Frenken K, Hellervik A, 2006, "A complex network approach to urban growth" Environment and Planning A 38(10) 1941 - 1964

Barabási A, Albert R, 1999, “Emergence of scaling in random networks” Science 286509

Bassens D, Derudder B, Witlox F, 2010, "Searching for the Mecca of finance: Islamic financial services and the world city network" Area 42 35-46

Borgatti SP, Everett MG, 1997, "Network analysis of 2-mode data" Social Networks 19(3) 243-269

Breiger R, 1974, “The duality of persons and groups” Social Forces 53 181-190

Conaldi G, Lomi A, Tonellato M, 2012, "Dynamic models of affiliation and the network structure of problem solving in an open source software project" Organizational Research Method DOI: $10.1177 / 1094428111430541$

Contractor N, Wasserman S, Faust K, 2006, "Testing multi-theoretical multilevel hypotheses about organizational networks: An analytic framework and empirical example" Academy of Management Review $31681-703$

Castells M, 2001, The Rise of the Network Society, Blackwell, Oxford.

Cooke P, Morgan K, 1993, "The network paradigm: new departures in corporate and regional development" Environment and Planning D: Society and Space 11(5) 543 - 564

Derudder B, Taylor P, Witlox F, Catalano G, 2003, "Hierarchical tendencies and regional patterns in the world city network: A global urban analysis of 234 Cities" Regional Studies 37 875-886

Derudder B, Taylor P, 2005, “The cliquishness of world cities” Global Networks 5 71-91

Derudder B, 2006, "On conceptual confusion in empirical analyses of a transnational urban network" Urban Studies 43(11) 2027-2046

Derudder B, Taylor P, Ni A, De Vos A, Hoyler M, Hanssens H, et al., 2010, "Pathways of change: Shifting connectivities in the world city network, 2000-08" Urban Studies 47 1861-1877

Desmarais B, Cranmer S, 2011, "Micro-level interpretation of Exponential Random Graph Models with application to estuary networks" Social Science Research Network, available at http://papers.ssrn.com/sol3/papers.cfm?abstract_id=1973620 (accessed at March 5, 2012)

Friedmann J, 1986, “The world city hypothesis” Development and Change 17 69-83

Gondal N, 2011, "The local and global structure of knowledge production in an emergent research field: An exponential random graph analysis" Social Networks 33 20-30

Huisman M, Snijders TAB, 2003, "Statistical analysis of longitudinal network data with changing composition" Sociological Methods \& Research 32 253-287 
Koskinen J, Edling C, 2011, "Modelling the evolution of a bipartite network-Peer referral in interlocking directorates" Social Networks doi:10.1016/j.socnet.2010.03.001

Latapy M, Megnien C, Del Vecchio N, 2008, "Basic notions for the analysis of large two-mode networks" Social Networks 30 31-48

Liu X, Taylor P, 2011, “A robustness assessment of GaWC global network connectivity ranking” Urban Geography 32 1227-37

Liu X, Derudder D, 2012, “Two-mode networks and the interlocking world city network model: A reply to Neal” Geographical Analysis 44 171-173.

Liu X, Derudder D, Liu Y, 2011, "GDP, livability, population, and income inequality of world cities" Environment and Planning A 43 2255-2256

Mahutga M, Ma X, Smith D, Timberlake M, 2010, "Economic globalisation and the structure of the world city system: the case of airline passenger data" Urban Studies 47 1925-1947

McCauley R, McGuire P, von Peter G, 2012, "After the global financial crisis: From international to multinational banking?" Journal of Economics and Business 64 7-23

Neal Z, 2008, "The duality of world cities and firms: Comparing networks, hierarchies, and inequalities in the global economy" Global Networks 8 94-115

Neal Z, 2012, "Structural determinism in the interlocking world city network" Geographical Analysis 44 $162-170$

Opsahl T, 2012, "Triadic closure in two-mode networks: Redefining the global and local clustering coefficients" Social Networks DOI:10.1016/j.socnet.2011.07.001.

Pain K, 2008, "Examining core-periphery relationships in a global mega-city region - The case of London and south east England" Regional Studies 42(8) 1161-1172

Pereira R, Derudder B, 2010, "Determinants of dynamics in the world city network, 2000-2004" Urban Studies 47 1949-1967

Ripley M, Snijders TAB, Preciado P, 2012 Manual for RSiena (University of Oxford: Department of Statistics; Nuffield College)

Robins G, Pattison P, Kalish Y, Lusher D, 2007, “An introduction to exponential random graph (p*) models for social networks" Social Networks 29 173-191

Sassen S, 2001 The Global City: New York, London (Princeton University Press, Princeton)

Schweinberger M, Snijders TAB, 2007, "Markov models for digraph panel data: Monte Carlo-based derivative estimation" Computational Statistics and Data Analysis 51 4465-4483

Schweinberger M, 2011, "Statistical modeling of network panel data: Goodness of fit" British Journal of Mathematical and Statistical Psychology DOI: 10.1111/j.2044-8317.2011.02022.x

Smith D, Timberlake M, 1993, "World cities: A political economy/ global network approach." Research in Urban Sociology 3 181-207. 
Snijders TAB, 2005. "Models for longitudinal network data", in Models and Methods in Social Network Analysis Carrington PJ, Scott J, Wasserman S (Cambridge University Press, New York) pp 215-247

Snijders TAB, Van de Bunt GG, Steglichc CEG, 2010, "Introduction to stochastic actor-based models for network dynamics" Social Networks 32, 44-60

Snijders TAB, Steglich CEG, Schweinberger M, 2007, "Modeling the co-evolution of networks and behavior", in Longitudinal Models in the Behavioral and Related Sciences Van Montfort K, Oud J, Satorra A(Lawrence Erlbaum, Mahwah, NJ) pp 41-72

Snijders TAB, 2001, "The statistical evaluation of social network dynamics", in Sociological Methodology Sobel ME, Becker MP (Basil Blackwell, Boston and London) pp 361-395

Snijders TAB, 1996, "Stochastic actor-oriented models for network change" Journal of Mathematical Sociology 21(1-2) 149-172

Taylor P, 2001, "Specification of the world city network" Geographical Analysis 33 181-194

Taylor P, 2004 World City Network: A Global Urban Analysis (Routledge, London, UK)

Taylor P, Derudder B, 2004, "Porous Europe: European Cities in Global Urban Arenas" Tijdschrift voor Economische en Sociale Geografie 95 527-538

Taylor P, Ni P, Derudder B, Hoyler M, Huang J, Witlox F, 2010, Global Urban Analysis: A Survey of Cities in Globalization (Earthscan, London)

Taylor P, Derudder B, Hoyler M, Ni P, 2012, "New regional geographies of the world as practised by leading advanced producer services firms in 2010" Transactions, Institute of British Geographers, accepted for publication.

Vinciguerra S, Frenken K, Valente M, 2010, “The geography of internet infrastructure: An evolutionary simulation approach based on preferential attachment" Urban Studies 47 1969-1984

Wall R, 2009 Netscape: Cities and Global Corporate Networks PhD thesis, Erasmus Research Institute of Management (ERIM)

Wang P, Sharpe K, Robins G, Pattison P, 2009, "Exponential random graph models for affiliation networks" Social Networks 31 12-25

Wang P, Pattison P, Robins R, 2012, "Exponential random graph model specifications for bipartite networks-A dependence hierarchy" Social Networks DOI:10.1016/j.socnet.2011.12.004

Warren TC, 2010, "The geometry of security: Modeling interstate alliances as evolving networks" Journal of Peace Research 47 697-709

Yeung $\mathrm{H} \mathrm{W}-\mathrm{C}, 2000$, "Embedding foreign affiliates in transnational business networks: the case of Hong Kong firms in Southeast Asia" Environment and Planning A 32(2) 201 - 222 